to recent genera, authors run considerable risk of misleading students who fail to appreciate the slender grounds on which such supposed affinity rests.

The volume issued by the Johns Hopkins Press is the best account of the Potomac flora so far produced, and the careful work of Mr. Berry, who is responsible for the greater share of the monograph, is deserving of warm praise.

A. C. Seward.

\section{THE LUMINOUS ORGANS OF CERTAIN INSECTS.}

I N The Canadian Entomologist (I9II, P. 399), Mr. interesting observations which afford strong confirmation of the view that the photogenic function in the Photinini is primarily a secondary sexual character; in at least four species in two of the genera, Lecontea and Photinus, the photogenic function serves undoubtedly as a mating adaptation. Direct observation showed that the female of, for example, Photinus pyralis responded by an answering flash to the flash of the flying male, which then dropped down, flashed again, and after her second answer alighted a few inches away from her, crawled towards her, flashing at intervals - to each of which flashes she responded-and finally located her.

It is interesting that in many cases it was possible to deceive the females in an open field by igniting a safety match and swinging it in an arc, so as to imitate the dipping flight and flash of the male pyralis. In each instance the flash of light from the match was answered within two to five seconds by the flashes of females of pyralis in the surrounding grass and weeds. By the use of a very small electric lamp it was found quite as easy to deceive the male pyralis. When a male flashed within about 2 or $3 \mathrm{ft}$. of the lamp, the circuit was closed two or three seconds afterwards by means of a push-button, so as to imitate as nearly as possible the intensity and time of flash of the female.

No definite instance was observed of a flying male mistaking the flash of a creeping male for that of a female and dropping to it. Observation on a single female of pyralis showed that she would not respond to the flash of a female Photuris pennsylvanica, Deg., made to flash above her, nor to a male of Photinus consanguincus, Lec., although the same female readily responded to a match. In the case of consanguineus, the female would answer a double flash of the lamp while some 20 or $30 \mathrm{ft}$. away, but on close approach seemed to recognise the difference and ceased to respond. Scintillans female also responds to the flash of the male consanguineus flying above her, but the latter appears to pay no attention to her.

In a second paper, in the Journal of the American Chemical Society (vol. xxxiii., p. I79r), Mr. McDermott deals with the chemical nature of the photogenic material, and shows that if the luminous organs of Photinus be dried in vacuo with a residual atmosphere of hydrogen, the tissue will retain its photogenic power and exhibit it when moistened eighteen months after preparation. If the dried tissue be moistened with 3 per cent. hydrogen peroxide a brighter light is produced than if water alone is used and the hydrogen peroxide is actively decomposed. If air is admitted to the sealed tubes containing the dried organs they rapidly lose their photogenic activity. When a living lampyrid was dropped into a test-tube immersed in liquid air it flashed rapidly for a few seconds, then fell back into the tube frozen stiff; meanwhile, the photogenic organ began to shine brilliantly, but the brilliancy rapidly diminished, the diminution being accompanied by a change in the colour of the light, which became reddish. The light finally disappeared, or very nearly so, but on warming to the room temperature it reappeared The insect was dead, but the tissue continued to glow for some time.

The probable chemical nature of the photogenic substance is discussed, and although there is very little reai evidence as to its nature, the hypothesis is put forward that it is probably an albuminous lipoid (phosphatide) which fairly readily undergoes oxidation.

\section{NATIONAL TEACHING OF SCIENCE SUBJECTS.}

$\mathrm{N}$ consequence of the issue by the Board of Education of Circular No. 776, which abolished examinations in the biological sciences, without providing any alternative scheme, the Physiological Society recently sent to the Board a memorandum directing attention to this action as a step gravely affecting national education in science. It was pointed out by the society that the cessation of the examinations in question, by withdrawing central guidance and inspiration, rendered it probable that unprofitable, inaccurate, and trivial courses of lessons would be given, and that in many cases it will lead to the abandonment of instruction in biological subjects in small centres. Moreover, it was insisted upon that development of the national teaching of science subjects, including biological subjects, necessitated an inquiry into the reorganisation of education in physics and chemistry.

With regard to the training of teachers, the memorandum dealt with the indispensable necessity of physics and chemistry as preliminary to physiology and with this science in turn as necessary for the rational understanding of hygiene, a subject which is already a part of the teacher's training, although no adequate provision for training in the necessary fundamental preliminary sciences is made.

Further, attention was directed to the fact that no teacher can possess a correct appreciation of psychology, or its application to national health and education, unless its study has been founded on a basis of physiology.

The Physiological Society, therefore, suggested to the Board of Education the desirability of suspending the operation of Circular No. 776 in order that reconsideration of its effects may be made by the Board, and especially directed attention to the necessity of reform in the scientific education of teachers and of the continuation of (reformed) examination in biological subjects (especially in physiology and hygiene) until a better method of ensuring adequate training in these sciences is established.

In forwarding this memorandum, the society requested that a deputation of its members should be received by the Board of Education. Accordingly, the President of the Board agreed to receive such a deputation on May I6. This deputation consisted of Sir Victor Horsley, Prof. Sherrington, Dr. Edkins, Prof. Starling, Dr. Waller, Dr. Myers, and Prof. Bayliss (hon. sec. of the society), and was introduced by Dr. Addison, M.P.

Sir Victor Horsley spoke chiefly on the absolute necessity of physics and chemistry as preliminary to hygiene. The training colleges were not teaching science in this wav, but were beginning with biological nature-study. The training in science should be given to all teachers, and bv them in turn to their punils in the elementary schools.

Prof. Sherrington, who has had much experience 
in the training of teachers, pointed out the impossibility of such students learning hygiene and applying it intelligently unless it was absolutely and strictly based on physiology, and that physiology could not be taught unless students had a preliminary knowledge of physics and chemistry.

Dr. Edkins insisted on the uselessness of teaching hygiene as a collection of health maxims, on the necessity that the teacher should know something of the material, bodily and mental, upon which he had to work, and that no teacher could do justice to the subject of hygiene or to the children taught if his or her qualification were simply rule-of-thumb knowledge and not genuine training in physical science.

Dr. Myers advocated the close coordination of the teaching of psychology and of the physiology of the nervous system and sense organs. Psychology should be included in every scheme of training college approved by the Board, and all psychology taught must have a basis of physiology.

The President of the Board of Education referred to the fact that the teaching of hygiene is universal in schools. He pointed out that the subjects taught in the training colleges were English language, literature and composition, history and geography, elementary mathematics, elementary science, the theory of music, principles of teaching, reading and repetition, drawing, needlework for women, singing and physical training, and that it would be very difficult to force other subjects upon these training colleges without sacrificing some of the subjects which the Board believed were more essential than the higher scientific subjects which the deputation desired to have taught. In conclusion, he informed the deputation that the Board thought that it ought to allow the effect of the Circular to be further realised before any step was taken in connection with it. The Board was not therefore prepared to suspend its operation.

\section{AMERICAN BULLETINS ON AGRICUL- TURAL SUBJECTS.}

THE results of the investigations carried out at the American experiment stations are issued as bulletins, and are sent out broadcast to all who are interested. Perhaps none of the institutions is more prolific than the Bureau of Entomology of the United States Department of Agriculture. In bulletin 97, part iv., Dudley Moulton describes the Californian peach borer (Sanninoidea opalescens, Hy. Edw.), which has been a constant menace to fruit-growers in certain districts. The adult moths fly from June to October, but are present in maximum numbers during July and August. The eggs are placed immediately after emerging, and after about two weeks the newly hatched larvæ enter the tree. The protective wash, a mixture of lime and tar oil, must therefore be applied before the middle of June. Carbon disulphide is used to a certain extent as an insecticide, but it has obvious disadvantages in that it is very volatile and combustible. Attempts have from time to time been made to replace it by a less dangerous liquid, and in bulletin 96 Messrs. Chittenden and Popenoe discuss the relative advantages of carbon tetrachloride and carbon disulphide as insecticides. It appears that the tetrachloride is less efficient and far more expensive, so that the problem is not as yet solved.

Bulletin No. Ir of the Michigan Agricultural College Experiment Station contains some experiments by D. G. Shafer, designed to ascertain how contact insecticides kill, a contact insecticide being one that works by enveloping the body in contradistinction to those that must be eaten to become effective. It NO. 2222 , VOL. 89$]$ appears that most of the vapours in use diffuse quickly into the insect tissues, and apparently reduce the oxygen absorption. If this conclusion is substantiated it will put the preparation of insecticides on a more scientific basis than has hitherto been possible.

Further observations on a bacterial disease of the pear, known as Hold-over blight, are reported by W. G. Sackett, of the Colorado Agricultural College. It appears that the prevalence of the disease in the arid western climate has been underestimated, and that careful watch will be necessary to prevent further spreading.

The special climatic conditions of New Mexicorainfall from six inches per annum upwards and a warm climate-necessitate a corresponding degree of specialisation at the agricultural experiment station there. Bulletin No. 78 describes the cacti that occur most commonly, and the uses to which some of them may be put; it is considered that they might be used to a greater extent than they are as stock food. Both spiny and spineless forms have been tried with some measure of success, but the Opuntia are by far the most important for this purpose, because of their abundance. The Cylindropuntias come next, but they multiply too slowly to be of much value. The advantage of the cactus is, of course, its ability to utilise a scanty and irregular water supply; its disadvantages are that it contains a good deal of saline matter to which animals do not readily become habituated. Methods are suggested by which the live stock can be trained to take more cactus than they do, so as to increase the output of food material from each farm.

\section{NOTEWORTHY WEATHER RECORDS.}

$A \mathrm{~N}$ interesting article on "The High Temperature $A$ of the Twelve Months May, I9II, to April, xg12," is published in Symons's Meteorological Magazinc for May. Dr. Mill points out that for the first time in the Camden Square (N.W. London) record there has been a run of twelve consecutive months in each of which the mean temperature has been above the average of fifty years. In IgII the month of April was the only one below the average. The mean temperature for the twelve months above quoted was $53 \cdot \mathrm{x}^{\circ}$, or $3 \cdot \mathrm{I}^{\circ}$ above the average. The nearest approach to this figure for any twelve successive months in the past fifty-four years was $52.8^{\circ}$ for the period March, I868, to February, I869. The most severe frosts of last winter occurred in the first week of February, but the unusual warmth of the latter part of the month raised the mean temperature $3.6^{\circ}$ above the average. March was also very remarkable for its warmth, both the mean temperature, $46.5^{\circ}$, and the mean shade minimum, $40.5^{\circ}$, being the highest on record for March. There were no frosts in the screen.

The same periodical also contains an article on the rainfall of April last. In our issues of May 2 and 9 it was stated that, so far as Greenwich is concerned, so small a monthly amount as 0.02 in. had not occurred in the last Ioo years. Referring to the rainfall over the whole of England, Dr. Mill states :"We may say with confidence that no previous April since the establishment of the British Rainfall Organisation has been so dry." An interesting map which accompanies the article shows that it was an exceptionally wet month in the west of Scotland, while, on the contrary, the east of Scotland had, for the most part, less than an inch of rain. In Ireland the rainfall was little under the average for the month. The map shows very clearly another instance of the frequent divergence of rainfall at opposite parts of the British Isles. 